\title{
An assessment of cervical spine injury associated with maxillofacial trauma: A retrospective study of 3 years
}

\author{
Kundan Shah ${ }^{1}$, Anand Mangalgi ${ }^{2}$, Neelam Singh ${ }^{3}$, Sudha Halkai ${ }^{4}$, Supriya Patil ${ }^{5}$ \\ 1,2,4,5 MDS, ${ }^{3}$ PG Student, ${ }^{1}$ Private Practioner, ${ }^{2-5}$ HKES's Nijalingappa Institute of Dental Sciences, Gulbarga, Karnataka, India \\ *Corresponding Author: \\ Email: shahkundan14@gmail.com
}

\begin{abstract}
Introduction: The incidence of cervical spine injuries associated with facial fractures varies from etiology to etiology. There is general concept that immediate management of cervical spine injuries is necessary to prevent further neurologic complications. However, disagreement exists as to the actual incidence of cervical spinal trauma in conjunction with various facial fracture patterns. The aim of this study was to assess the incidence of cervical spine injury associated with various types of facial fractures at our institution.

Materials and Method: A retrospective study was conducted at our institution of cranio maxillofacial fracture patients presenting from January 1, 2015, to December 31, 2017.

Results: The data from this 3-year time period revealed a total of 62 patients with cervical spine injuries out of 456 patients presenting with cranio maxillofacial fractures. The overall incidence of cervical spine injury was 13.59 percent. Of these patients, 18 had isolated upper third facial or skull fractures, whereas isolated middle third facial fractures were seen in 148 patients and isolated lower third facial fractures were present in 251 patients. Combined facial fracture patterns, involving two or more facial thirds, accounted for39 patients.

Conclusions: The relationship between cervical spinal injuries and cranio maxillofacial trauma has been better defined as it relates to a regional trauma registry. The implications as related to the trauma assessment, diagnosis, and treatment of these injuries are reviewed.
\end{abstract}

Keywords: Maxillofacial injuries, Incidence, Cervical spine injury.

\section{Introduction}

Maxillofacial trauma is regarded as injuries with higher risk for concomitant cervical spine injury. ${ }^{1,2}$ The presence or absence of a cervical spine injury (CSI) has important implications in trauma patients, influencing airway management techniques, choice of diagnostic imaging studies, surgical approach and timing for repair of associated facial fractures. Most injuries of the cervical spine associated with facial fractures are due to forces transmitted directly or indirectly from the facial skeleton to the cervical bony and connective tissue structures. ${ }^{3,4}$ Those suffering high velocity injuries such as road traffic accidents (RTAs) are presumed to be at higher risk for cervical spine trauma than those sustaining lower velocity injuries as seen in falls and workplace accidents. ${ }^{5-8}$

The aim of this study was to determine the incidence and patterns of CSI associated with maxillofacial fractures admitted at a Indian tertiary referral trauma centre.

\section{Materials and Method}

A retrospective study was performed of all the patients presented with maxillofacial injuries etween $1^{\text {st }}$ January 2015 and $31^{\text {st }}$ December 2017 at our institution which is a tertiary referral trauma centre. All the patients with maxillofacial trauma were divided into 2 groups:

Group A: Patient with maxillofacial trauma without associated cervical spine injury
Group B: Patient with maxillofacial trauma with associated cervical spine injury (CSI).

The findings were confirmed using 3D CT reconstruction view for maxillofacial trauma and included fracture of upper $1 / 3^{\text {rd }}$, middle $1 / 3^{\text {rd }}$, lower $1 / 3^{\text {rd }}$ and combined fractures.

CSI was characterised according to level of injury confirmed by radiography, and included fractures, dislocations and subluxations. Cord compression, cord contusion anddisc herniation were also noted.

\section{Results}

A total of 456patients with maxillofacial fractures were identified in the 3-year study period. The patient age range in this group was from 16 to 83 years with maximum of cases between 21 to 30 years of age (Table 1) and there was a male-to-female ratio of 24:1(Graph 1).

Among the 456 patients included in the study, 62 patients had associated cervical spine injury (13.59\%) and 394 patients had only maxillofacial injury (Graph 2 and 3).

The major etiological factor was road traffic accident which accounted for 444 cases followed by assaults 7 cases and others (Table 2).

Among 456 cases the incidence of maxillofacial injury was maximum for lower $1 / 3^{\text {rd }}$ of the face accounting for a total of 251 cases followed by the middle $3^{\text {rd }}$ with 148 cases (Graph 4) 
The incidence of involvement of cervical spine shows that $\mathrm{C} 2$ was involved the most (Graph 5)

Accounting for the type of cervical spine injury subluxation was most common followed by fracture (Graph 6).

Table 1: Age wise distribution of cases

\begin{tabular}{|l|c|c|}
\hline Age group & No. of cases & $\begin{array}{c}\text { Percentage } \\
\text { of cases }\end{array}$ \\
\hline$<=20$ & 16 & $4 \%$ \\
\hline $21-30$ & 212 & $46 \%$ \\
\hline $31-40$ & 138 & $30 \%$ \\
\hline $41-50$ & 71 & $16 \%$ \\
\hline$>=51$ & 19 & $4 \%$ \\
\hline
\end{tabular}

Graph 1: Gender wise distribution of cases

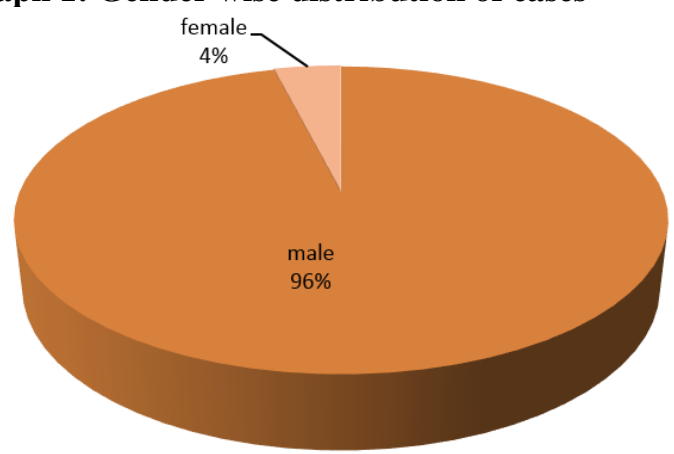

Graph 2: Association of maxillofacial fractures with cervical spine injury

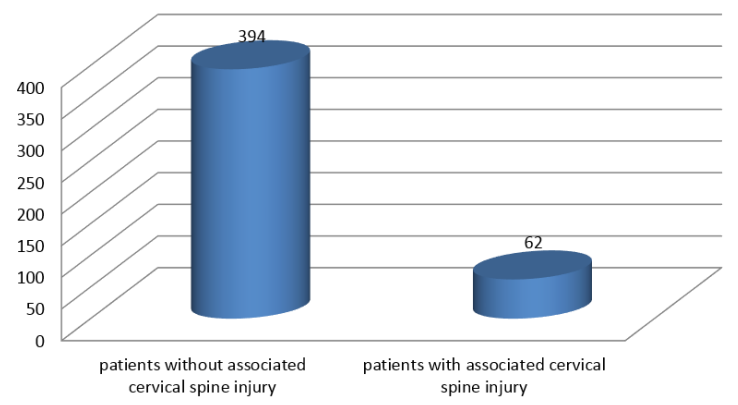

Graph 3: Association of cervical spine injury with maxillofacial fractures

mpatient without cervical spine injury a patient with cervical spine injury

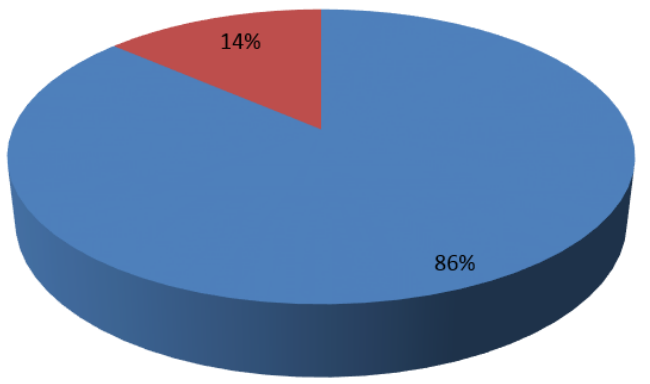

Table 2: Etiology wise distribution of cases

\begin{tabular}{|l|l|c|}
\hline S. No. & \multicolumn{1}{|c|}{ Etiology } & $\begin{array}{c}\text { No. of } \\
\text { patients }\end{array}$ \\
\hline 1. & Road traffic accident (RTA) & 444 \\
\hline 2. & Assaults & 7 \\
\hline 3. & Fall from height & 2 \\
\hline 4. & Automobiles injury & 1 \\
\hline 5. & Others & 2 \\
\hline
\end{tabular}

Graph 4: Case distribution based on type of maxillofacial trauma

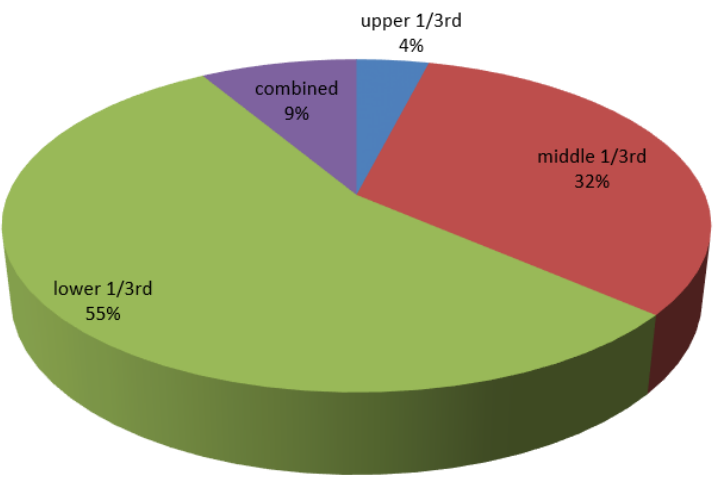

Graph 5: Representation of the spinal cord involved

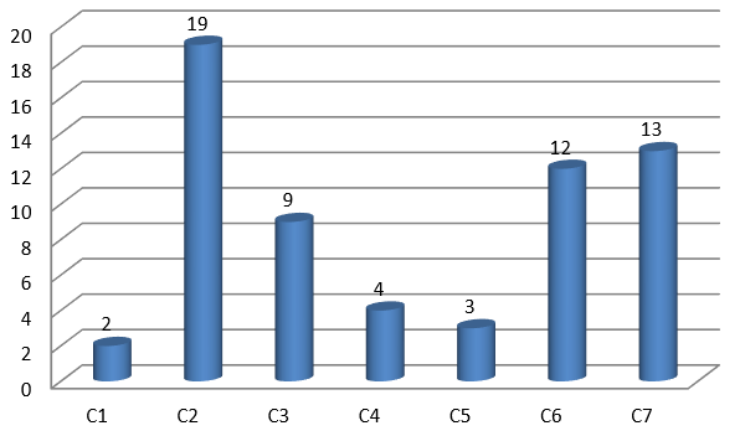

Graph 6: No. of patients based on type of cervical spine injury

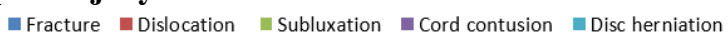

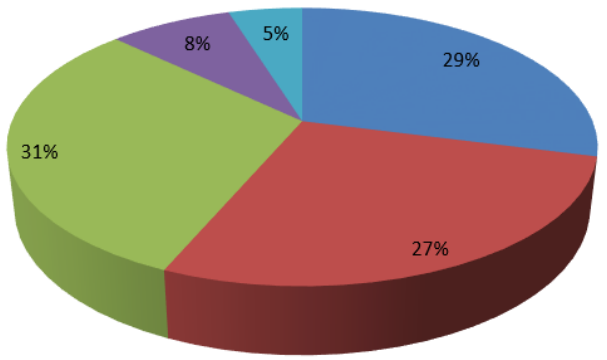

Discussion

Patients with maxillofacial fractures are at risk ofassociated cervical spine or spinal cord injury. ${ }^{2}$

Most injuries of the cervical spine associated with facial fractures are attributed to forces transmitted 
directly or indirectly from the facial skeleton to the cervical bony and connective tissue structures. ${ }^{3,4}$

Maxillofacial fractures often result from highenergy force injury to the facial skeleton, typically from road traffic accidents, altercations and falls 9. With increased legislation requiring seat belt use, injuries from the driver hitting the steering wheel have shifted from chest trauma to facial trauma.

The majority of studies have reported wide variations in the incidence of cervical spine injury in maxillo-facial trauma patients, ranging between 0 and $8 \%$, but the incidence of cervical spine injury in our study has been recorded as high as $13.59 \%$ which was in line with the study in the literature. 10 The variation in incidence of cervical spine injury is not only the result of differences in the mechanism of injury 3,4 but also the anatomical location of impact11,12location of trauma centre1,10and patient demographics including age and gender 13,14,15. Trauma protocols including the Advanced Trauma Life Support Manual (Advanced Trauma Life Support, 2008) stress the importance of the association between maxillofacial and cervical spine injuries and the catastrophic consequences that can ensue if the diagnosis is missed or its presence or absence ignored.

The majority of cervical spine injuries are seen in association with road traffic accidents, high falls and other traumatic scenarios such as workplace accidents or assault) - this most likely reflects the greater velocity and therefore force of impact to the face, since force is a product of mass and acceleration ${ }^{3,4,7}$ with was in accordance to our study where RTA was main etiology.

It is known that high-velocity impacts are required to fracture the structures of the frontal and supraorbital ridges, whereas relatively weaker forces can fracture the skull. This discrepancy is responsible for a relatively higher frequency of cervical spine injuries seen with isolated upper third facial fractures vs isolated skull, middle third and lower thirdfacial fractures (Elahi et al, 2008). Intuitively, one can expect that fractures of the most cephalic portion of the facial skeleton, because of the high resistance to impact, would be associated with more severe associated injuries.

The risk of cervical spine injury is higher in association with combined facial fractures involving more than one facial bone. A large study on over 1.3 million trauma patients from the United States and Puerto Rico found that in the setting of two or more facial fractures, the prevalence of cervical spine injury ranged from $7.0 \%$ to $10.8 \%$ while in the setting of an isolated mandible, nasal, orbital floor, malar or maxilla, or frontal or parietal bone fracture, cervical spine injury ranged from $4.9 \%$ to $8.0 \%$. These findings most likely reflect the greater impact and force of injury involved when two or more facial regions have been fractured compared with one isolated facial region, which is then transmitted to the neck causing cervical spinal injury. In particular, Le Fort facial fractures (I, II, III)have been associated with increased risk of cervical spine injury 8,14 .

Various authors have reported a correlation between mandibular fractures and cervical spine injuries which was in accordance with our study. 3,7

Cervical spine injuries occur at two main levels: the $\mathrm{C} 1-\mathrm{C} 2$ and $\mathrm{C} 6-\mathrm{C} 7$ intervals. A Canadian study by Elahi et al (2008) described a 67\% share of 124 cervical spine injuries associated with maxillofacial trauma occurring at the C1-C2 and C6-C7 levels. They also found an increasing frequency of disc herniation and cord contusion as one travels in a cephalic to caudal direction along the cervical spine, which may be the result of accentuation of direct and indirect forces transmitted from the facial skeleton farther down the spinal cord 3. As in our study c2 was most commonly involved.

\section{Conclusion}

To conclude, any patient with a maxillofacial injury should be suspected of having a cervical spine injury, and as such, mandatory cervical spinal immobilization together with radiographical assessment of the cervical spine is required. However, clearance of spinal injury in patients with multiple trauma and associated maxillofacial injuries can be difficult. A clear systematic approach can help to minimize the consequences of missing a spinal injury. Determining which radiological study to order for a potential cervical spine injury is critical. Patients who do not have altered mental status, a neurological deficit, intoxication, neck pain or midline tenderness, or an associated distracting injury do not require radiographical assessment. The presence of a craniofacial fracture requires mandatory radiological assessment of the cervical spine.

\section{References}

1. Baker AB, Mackenzie W. Facial and cervical injuries. Med J Aust 1976;1:236-7.

2. Beirne JC, Butler PE, Brady FA. Cervical spine injuries in patients with facial fractures: a 1-year prospective study. Int J Oral Maxillofac Surg 1995;24:26-9.

3. Ardekian L, Gaspar R, Peled M et al. Incidence and type of cervical spine injuries associated with mandibular fractures. J Craniomaxillofac Trauma 1997;3:18-21.

4. Davidson JS, Birdsell DC. Cervical spine injury in patients with facial skeletal trauma. J Trauma 1989;29:1,276-1,278.

5. Haisová L, Krámová I. Facial bone fractures associated with cervical spine injuries. Oral Surg Oral Med Oral Pathol 1970;30:742-8.

6. Lewis VL, Manson PN, Morgan RF et al. Facial injuries associated with cervical fractures: recognition, patterns, and management. J Trauma 1985;25:90-3.

7. Merritt RM, Williams MF. Cervical spine injury complicating facial trauma: incidence and management. Am J Otolaryngol 1997; 18: 235-8. 
8. Williams J, Jehle D, Cottington E, Shufflebarger C. Head, facial, and clavicular trauma as a predictor of cervicalspine injury. Ann Emerg Med 1992;21: 719-22.

9. Aksoy E, Unlu E, Sensoz O (2002) A retrospective study on epidemiology and treatment of maxillofacial fractures. J Craniofac Surg 13:772-5.

10. Bucholz RW, Burkhead WZ, Graham W, Petty C (1979) Occult cervical spine injuries in fatal traffic accidents. $J$ Trauma 19:768-71.

11. Gwyn PP, Carraway JH, Horton CE, Adamson JE, Mladick RA (1971) Facial fractures: Associated injuries and complications. Plast Reconstr Surg 47:225-30.
12. Haug RH, Wible RT, Likavec MJ, Conforti PJ (1991) Cervical spine fractures and maxillofacial trauma. J Oral Maxillofac Surg 49:725-9.

13. Reiss SJ, Raque GH Jr, Shields CB, Garretson HD (1986) Cervical spine fractures with major associated trauma. Neurosurgery 18:327-30.

14. Sinclair D, Schwartz M, Gruss J, McLellan B (1988) A retrospective review of the relationship between facial fractures, head injuries, and cervical spine injuries. $J$ Emerg Med 6:109-12.

15. Williams J, Jehle D, Cottington E, Shufflebarger C (1992) Head, facial, and clavicular trauma as a predictor of cervical-spine injury. Ann Emerg Med 21:719-22. 